\title{
Optimization of Polysaccharide Extraction from Polygonatum odoratum by Response Surface Methodology and Evaluation of its Antitumor Activity
}

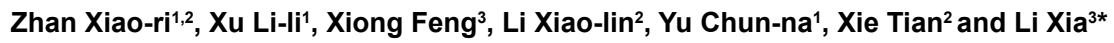

${ }^{1}$ College of Life and Environment Science, Hangzhou Normal University, Hangzhou 310036, People's Republic of China

${ }^{2}$ Resource Center for Chinese Materia Medica, China Academy of Chinese Medical Sciences, Beijing, People's Republic of China

${ }^{3}$ Guangxi Key Laboratory of Electrochemical and Magneto-chemical Functional Materials, College of Chemistry and Bioengineering, Guilin University of Technology, Guilin, Guangxi 541004, People's Republic of China

\begin{abstract}
This work established a microwave-assisted procedure for polysaccharide extraction from Polygonatum odoratum. Response surface methodology was used to optimize microwave-assisted extraction parameters (extraction temperature, water-to-raw material ratio, microwave power, and extraction time) by implementing a three-level, fourvariable Box-Behnken experimental design in a single-factor investigation. Three-dimensional response surfaces were plotted by Design-Expert, and result indicated the absence of interaction effects of extraction temperature and microwave power. A polysaccharide yield of approximately $17.49 \%$ was obtained under the following optimized conditions: temperature of $57^{\circ} \mathrm{C}$, microwave power of $300 \mathrm{~W}$, extraction time of $10 \mathrm{~min}$, and water-to-raw material ratio of 23:1. The results of preliminary in vitro antitumor activity tests showed that polysaccharides derived from $P$. odoratum could inhibit growth of A549 cells in a dose-dependent manner. Moreover, $4-400 \mu \mathrm{g} / \mathrm{mL}$ of these polysaccharides exerted no significant cytotoxicity to Panc-1 cells.
\end{abstract}

Keywords: Microwave-assisted extraction; Polysaccharides; Polygonatum odoratum; Response surface methodology

\section{Introduction}

Polysaccharides are essentially polymeric carbohydrates consisting of monosaccharides linked by glycosidic bonds. Depending on their structure, polysaccharides display functional properties distinct from those of their constituent monosaccharides; as a result, they play a wide array of important roles in nature [1]. Plant-derived polysaccharides demonstrate a variety of biological properties, including anti-oxidative [2-4], anti-viral [5], and anti-complementary activities [6,7]. Over the years, polysaccharides have become important raw materials for health foods, drugs, and cosmetics.

Rhizoma Polygonati Odorati (Fragrant Solomonseal Rhizome, Yu $\mathrm{Zhu}$ ) is the dried rhizome of Polygonatum odoratum (Mill.), which has been used for centuries in traditional herbal medicine as an important source of medicine and as base for a valuable nourishing tonic. The Ministry of Health of the People's Republic of China has defined $P$. odoratum as an affinal drug and a diet material. Traditionally, $P$. odoratum is described to possess the capability to nourish the yin and to promote fluid production to quench thirst. This medicinal plant is applied to treat diabetes, palpitations, lung illnesses, and upset stomachs. Currently, P. odoratum is usually used as a functional food given that long-term consumption of this plant does not damage the stomach [8-10]. P. odoratum contains various chemical components, such as polysaccharides, flavonoids, steroidal saponins, and alkaloids. Studies have shown that $P$. odoratum polysaccharides (POP) demonstrate immunological, anti-tumor, and anti-aging activities [11]. However, studies on POP extraction remain low.

Microwave assists in solvent extraction of bioactive compounds from herbs [12-15]. Microwave extraction has many advantages, including reduced consumption of organic solvent and shorter extraction time. Thus, microwave extraction is more effective than traditional extraction methods.

When many factors and interactions affect desired response, response surface methodology (RSM) is an effective tool for optimizing the process, which was originally described by Box and Wilson. RSM is a collection of statistical and mathematical techniques used to determine the effects of several variables and to optimize various processes [16]. RSM has been successfully applied to optimize conditions in food and pharmaceutical research $[16,17]$. The main advantage of RSM is the reduced number of experimental trials needed to evaluate multiple variables and their interactions. Therefore, it is less laborious and time consuming than other approaches required optimizing a process. Usually, it applies an experimental design such as Box-Behnken (BBD), central composite (CCD) and Doehlert designs (DDD) to fit a secondorder polynomial by a least squares technique. An equation is used to describe how the test variables affect the response and determines the interrelationship among the variables.

This study investigated significant variables (ratio of water to raw material, extraction temperature, extraction time, microwave power) and further optimize the extraction process of polysaccharides from $P$. odoratum using RSM, while employing a three-level, four-variable BBD. Inhibitory effect of POP extraction on A549 and Panc-1 cell lines was investigated.

*Corresponding author: Xia Li, Guangxi Key Laboratory of Electrochemical and Magneto-chemical Functional Materials, College of Chemistry and Bioengineering, Guilin University of Technology, Guilin, Guangxi 541004, People's Republic of China, Tel: +8618107735083; Fax:+865896839; E-mail: biology754@163.com

Received November 22, 2016; Accepted December 12, 2016; Published December 15, 2016

Citation: Xiao-ri Z, Li-li X, Feng X, Xiao-lin L, Chun-na Y, et al. (2016) Optimization of Polysaccharide Extraction from Polygonatum odoratum by Response Surface Methodology and Evaluation of its Antitumor Activity. J Bioprocess Biotech 6: 292 doi:10.4172/2155-9821.1000292

Copyright: (c) 2016 Barathikannan K, et al. This is an open-access article distributed under the terms of the Creative Commons Attribution License, which permits unrestricted use, distribution, and reproduction in any medium, provided the original author and source are credited. 
Citation: Xiao-ri Z, Li-li X, Feng X, Xiao-lin L, Chun-na Y, et al. (2016) Optimization of Polysaccharide Extraction from Polygonatum odoratum by Response Surface Methodology and Evaluation of its Antitumor Activity. J Bioprocess Biotech 6: 292. doi:10.4172/2155-9821.1000292

Page 2 of 8

\section{Materials and Methods}

\section{Materials and reagents}

A549 lung adenocarcinoma cells and Panc-1 human pancreatic carcinoma cells were obtained from the Department of Research Center for Biomedicine and Health, Hangzhou Normal University (Hangzhou).

3-(4,5-Dimethylthiazol-2-yl)-2,5-diphenyl-tetrazolium bromide (MTT) and dimethyl sulfoxide (DMSO) were purchased from Sigma-Aldrich Co. (St. Louis, MO, USA). RPMI 1640 and FBS were obtained from Gibco. MAS-I Microwave Synthesis System was obtained from Shanghai Sineo Microwave Chemistry Technology Co., Ltd (Shanghai).

\section{Preparation of POP}

P. odoratum was dried at $40^{\circ} \mathrm{C}$ for $48 \mathrm{~h}$ and then pulverized in a blender to obtain a fine powder (particle diameter is $<500 \mu \mathrm{m}$ ). The pulverized $P$. odoratum was soaked in $95 \%$ ethanol twice for defatting and removal of colored materials, oligosaccharides, and small molecules.

Each pretreated dried sample $(5.0 \mathrm{~g})$ was extracted with water under specified extraction temperature, water-to-raw material ratio, microwave power, and extraction time. The water extraction solutions were centrifuged at $3000 \mathrm{rpm}$ for $15 \mathrm{~min}$, and then the supernatant was separated from insoluble residue with four-layer filter cloth, which were precipitated by the addition of ethanol to a final concentration of $80 \%(\mathrm{v} / \mathrm{v})$ and incubated overnight. The precipitates collected through centrifugation (3000 rpm for $15 \mathrm{~min}$ ) were washed three times with dehydrated alcohol and ethyl ether and then dried under reduced pressure to obtain crude polysaccharides.

\section{Determination of polysaccharides yield}

The polysaccharide content was determined through the phenolsulfuric acid method by using D-glucose as standard [18]. The crude polysaccharides were accurately weighed and dissolved in distilled water in a $100 \mathrm{~mL}$ volumetric flask. Afterwards, the sample solution was carefully transferred into a $10 \mathrm{~mL}$ cuvette. Phenol $(5 \%, 1 \mathrm{~mL})$ was added into the cuvette and then shaken. Sulfuric acid $(7.0 \mathrm{~mL})$ was subsequently added into the mixture, shaken, incubated at $40^{\circ} \mathrm{C}$ in a water bath for $30 \mathrm{~min}$, and then allowed to stand in an ice bath for 5 min. Absorbance values were recorded by a UV spectrophotometer at $490 \mathrm{~nm}$. The wash solution served as blank control and was measured in a similar manner. The regression equation between microgram value of glucose and OD value were obtained as: $A=6.0667 \mathrm{C}+0.1078$ (A: 490 $\mathrm{nm}$ OD, C: $\mu \mathrm{g} / \mathrm{mL}), \mathrm{r}=0.9972$; linearity range: $10-40 \mu \mathrm{g} / \mathrm{mL}$.

\section{Experimental design}

After the range of extraction variables was preliminarily determined through a single-factor test, a three-level BBD was performed using four independent variables (X1, extraction temperature; $\mathrm{X} 2$, water-toraw material ratio; X3, microwave power; and X4, extraction time). For statistical calculation, the variables were coded according to

$$
x_{i}=\frac{X_{i}-X_{0}}{\Delta X_{i}}
$$

where $\chi_{i}$ is a coded value of a variable; $X_{i}$ is the actual value of a variable; $\mathrm{X}_{0}$ is the actual value of $\mathrm{X}_{\mathrm{i}}$ at the center point; and $\Delta \mathrm{X}_{\mathrm{i}}$ is the step change value. Table 1 shows the range of independent variables and their levels. The independent variables and their ranges were determined in our preliminary experiments. Three experiments for each condition were performed and the mean values were considered as observed responses. The complete design consisted of 27 experimental points, and the experiments were performed in a random order (Table 2).

Data from the $\mathrm{BBD}$ were analyzed by multiple regressions to fit the following quadratic polynomial model.

$$
\mathrm{Y}=\beta_{0}+\sum_{i=1}^{\mathrm{k}} \beta_{i} X_{i}+\sum_{i=1}^{\mathrm{k}} \beta_{i} X_{i}^{2}+\sum_{i=1}^{k-1} \sum_{j>i}^{k} \beta_{j} X_{i} X_{j}
$$

$\mathrm{Y}$ represents the response function. $\beta_{0}$ is an intercept. $\beta_{i}, \beta_{i i}$, and $\beta_{i j}$ are the coefficients of the linear, quadratic, and interactive terms, respectively. $\chi_{i}$ and $\chi_{j}$ represent the coded independent variables, respectively. The fitted polynomial equation was expressed as surface and contour plots to visualize the relationship between the response and experimental levels of each factor and to deduce the optimum conditions [19]. The regression coefficients of individual linear, quadratic, and interaction terms were determined through analysis of variance. These regression coefficients were used in statistical calculation to generate dimensional and contour maps from the regression models. Designexpert version 8.0.4 (Trial Version, State-Ease Inc., Minneapolis, MN, USA) was used to analyze the experimental data. P-values of less than 0.05 indicated statistical significance.

\section{Cytotoxicity assay in vitro}

POP was dissolved in distilled water at a concentration of 10 $\mathrm{g} / \mathrm{L}$ and then filtered through a $0.22 \mu \mathrm{m}$ filter and stored at $4^{\circ} \mathrm{C}$. The solution was further diluted to different concentrations $(800 \mu \mathrm{g} / \mathrm{mL}, 80$ $\mu \mathrm{g} / \mathrm{mL}, 8 \mu \mathrm{g} / \mathrm{mL}$ ) with RPMI 1640 medium in tissue plates separately.

Cell proliferation was analyzed through colorimetric MTT assay as described previously [20]. Briefly, cells were seeded in a 96-well microplate $\left(1 \times 10^{4}\right.$ cells/well, in a volume of $\left.100 \mu \mathrm{L}\right)$, treated with or without $5-\mathrm{Fu}(1 \mu \mathrm{g} / \mathrm{mL})$, DDP $(10 \mu \mathrm{g} / \mathrm{mL})$ and incubated in RPMI 1640 medium containing $10 \%$ FBS with $100 \mu \mathrm{L}$ sample polysaccharides at a concentration of $400 \mu \mathrm{g} / \mathrm{mL}, 40 \mu \mathrm{g} / \mathrm{mL}, 4 \mu \mathrm{g} / \mathrm{mL}$. The experiments were performed in triplicate. The cells were subsequently incubated at $37^{\circ} \mathrm{C}$ under a humidified $5 \% \mathrm{CO}_{2}$ atmosphere.

MTT $(5 \mathrm{mg} / \mathrm{mL}, 20 \mu \mathrm{L})$ was added after $72 \mathrm{~h}$. After the plates were incubated at $37^{\circ} \mathrm{C}$ for $4 \mathrm{~h}$, the supernatant was aspirated and $150 \mu \mathrm{L}$ of DMSO was added into each well. Absorbance was measured at $570 \mathrm{~nm}$ by a $96-$-well microplate reader (Bio-Rad, USA). The inhibition rate of cell growth was calculated as follows:

(mean value for control group-mean value for treated group)/ control group $\times 100 \%$.

\section{Results and Discussion}

\section{Effect of extraction temperature on extraction yield of polysaccharides}

Different extraction temperature was set at $30,40,50,60$ and $70^{\circ} \mathrm{C}$, respectively, to investigate the influence of extraction temperature on the yield of POP. The other reaction conditions were as follows: water-to-raw material ratio of 20:1, microwave power of $200 \mathrm{~W}$, and extraction time of $10 \mathrm{~min}$. Figure 1a indicates that the maximum yield was obtained when the extraction temperature was increased from $40^{\circ} \mathrm{C}$ to $50^{\circ} \mathrm{C}$. However, when the extraction temperature was further increased, the yield declined linearly. Therefore, the optimal extraction temperature adopted in this work is $50^{\circ} \mathrm{C}$. 


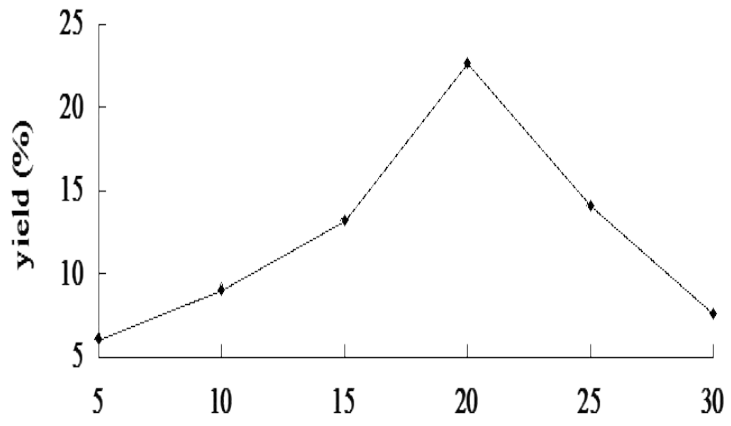

ratio of water to raw material

A

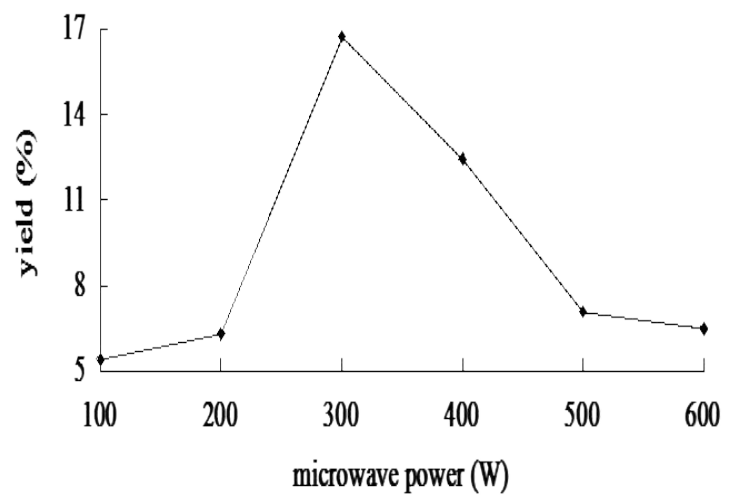

$\mathrm{C}$

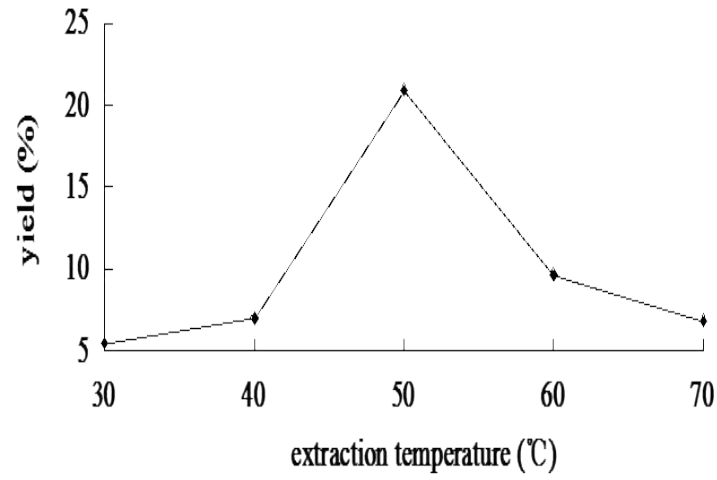

$\mathrm{B}$

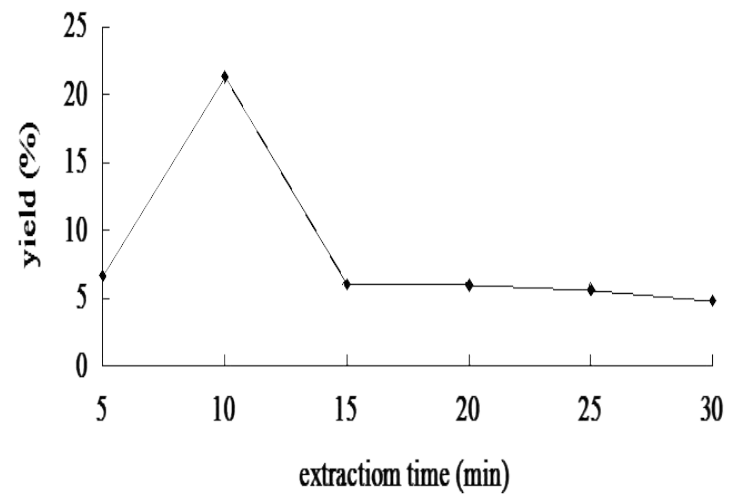

$\mathrm{D}$

Figure 1: Effect of different extraction parameters (a: ratio of water to raw material; b: extraction temperature, ${ }^{\circ} \mathrm{C}$; c: microwave power, $\mathrm{W}$; d: extraction time, min) on yield of polysaccharides.

\section{Effect of water to raw material ratio on extraction yield of polysaccharides}

Figure $1 \mathrm{~b}$ shows the effect of different water-to-raw material ratios $(5: 1,10: 1,15: 1,20: 1,25: 1$, and 30:1) on POP yield. When the extraction temperature $\left(50^{\circ} \mathrm{C}\right)$, microwave power $(200 \mathrm{~W})$, and extraction time $(10$ min) were set at level 0 , the yield suddenly increased to the critical value of $22.68 \%$ under $20: 1$ ratio. This result indicated that when the ratio is higher than 20:1, the polysaccharide yield decreases possibly because polysaccharides can be excessively dissolved in low-concentration solvent, resulting in considerable yield loss during product collection. Therefore, the water-to-raw material ratio of 20:1 was adopted in the following work.

Effect of microwave power on the extraction yield of polysaccharides

Figure 1c shows the effect of microwave power on POP yields. When the extraction temperature, water-to-raw material ratio, and extraction time were set at $50^{\circ} \mathrm{C}, 20: 1$, and $10 \mathrm{~min}$, respectively, the yield obviously increased under microwave power of 100-600 W. The polysaccharide yield was $16.74 \%$ when the samples were extracted at $300 \mathrm{~W}$. However, the yield decreased significantly when the microwave power further increased, indicating that $200 \mathrm{~W}$ is sufficient for polysaccharide extraction in the present work.

\section{Effect of extraction time on extraction yield of polysaccharides}

Extraction time influences the extraction efficiency and selectivity of a fluid. A longer extraction time increases polysaccharide yields $[21,22]$. This study investigated the effect of extraction time $(5,10$, $15,20,25$, and $30 \mathrm{~min}$ ) on polysaccharide yield when the extraction temperature is $50^{\circ} \mathrm{C}$, water-to-raw material ratio is $20: 1$, and microwave power is $200 \mathrm{~W}$. Figure $1 \mathrm{~d}$ shows that the maximum yield was obtained when the extraction time was $10 \mathrm{~min}$; beyond this period, the yield decreased significantly; more over a descending dynamic equilibrium was observed with extended extraction time. Therefore, the extraction time used in this work is $5-15 \mathrm{~min}$.

\section{Optimization of the extraction parameters of polysaccharides}

Statistical analysis and the model fitting: RSM optimization is more advantageous than the traditional single-parameter optimization because the former saves time, space, and raw materials [23]. A total of 29 runs were performed to optimize the four individual parameters in BBD. Table 2 shows the experimental conditions and the polysaccharide yields according to the factorial design. By applying multiple regression analysis on the experimental data, the response variables and the test variables were related by the following second-order polynomial equation: 
Citation: Xiao-ri Z, Li-li X, Feng X, Xiao-lin L, Chun-na Y, et al. (2016) Optimization of Polysaccharide Extraction from Polygonatum odoratum by Response Surface Methodology and Evaluation of its Antitumor Activity. J Bioprocess Biotech 6: 292. doi:10.4172/2155-9821.1000292

\begin{tabular}{|c|c|c|c|}
\hline \multirow{2}{*}{ Independent variables } & \multicolumn{3}{|c|}{ Factor level } \\
\cline { 2 - 4 } & $-\mathbf{1}$ & $\mathbf{0}$ & $\mathbf{1}$ \\
\hline $\mathbf{X}_{\mathbf{1}}:$ Extraction temperature $\left({ }^{\circ} \mathbf{C}\right)$ & 40 & 50 & 60 \\
\hline $\mathbf{X}_{\mathbf{2}}:$ Ratio of water to raw material & 15 & 20 & 25 \\
\hline $\mathbf{X}_{\mathbf{3}}:$ Microwave power $(\mathbf{W})$ & 200 & 300 & 400 \\
\hline $\mathbf{X}_{\mathbf{4}}$ : Extraction time $(\mathbf{m i n})$ & 5 & 10 & 15 \\
\hline
\end{tabular}

Table 1: Independent variables and their levels used in the response surface design.

\begin{tabular}{|c|c|c|c|c|c|}
\hline Run & $x_{1}$ & $X_{2}$ & $X_{3}$ & $x_{4}$ & Yield (\%) \\
\hline 1 & 1 & 0 & 0 & -1 & 13.98 \\
\hline 2 & 0 & -1 & 1 & 0 & 9.26 \\
\hline 3 & -1 & 0 & -1 & 0 & 6.99 \\
\hline 4 & -1 & -1 & 0 & 0 & 11.07 \\
\hline 5 & 0 & 0 & 1 & -1 & 9.24 \\
\hline 6 & 0 & 0 & 0 & 0 & 16.74 \\
\hline 7 & 1 & 0 & 1 & 0 & 10.58 \\
\hline 8 & 0 & -1 & -1 & 0 & 2.37 \\
\hline 9 & -1 & 0 & 1 & 0 & 7.07 \\
\hline 10 & -1 & 0 & 0 & 1 & 10.27 \\
\hline 11 & 1 & -1 & 0 & 0 & 1.12 \\
\hline 12 & 0 & 0 & -1 & 1 & 6.02 \\
\hline 13 & 1 & 0 & -1 & 0 & 9.68 \\
\hline 14 & 0 & 0 & 0 & 0 & 16.74 \\
\hline 15 & 0 & -1 & 0 & -1 & 3.37 \\
\hline 16 & 0 & 0 & 1 & 1 & 10.83 \\
\hline 17 & 0 & 0 & -1 & -1 & 10.22 \\
\hline 18 & 1 & 0 & 0 & 1 & 8.80 \\
\hline 19 & 1 & 1 & 0 & 0 & 17.23 \\
\hline 20 & 0 & 0 & 0 & 0 & 16.74 \\
\hline 21 & 0 & 1 & 1 & 0 & 8.84 \\
\hline 22 & 0 & 0 & 0 & 0 & 16.74 \\
\hline 23 & 0 & 1 & 0 & 1 & 13.75 \\
\hline 24 & 0 & 1 & 0 & -1 & 6.56 \\
\hline 25 & 0 & 1 & -1 & 0 & 9.54 \\
\hline 26 & -1 & 1 & 0 & 0 & 1.16 \\
\hline 27 & 0 & 0 & 0 & 0 & 16.74 \\
\hline 28 & 0 & -1 & 0 & 1 & 4.06 \\
\hline 29 & -1 & 0 & 0 & -1 & 5.03 \\
\hline
\end{tabular}

Table 2: Box-Behnken experimental design and results for extraction yield.

$\mathrm{Y}=16.78+1.62 \times \mathrm{X}_{1}+1.61 \times \mathrm{X}_{2}+0.92 \times \mathrm{X}_{3}-0.097 \times \mathrm{X}_{4}+6.59 \times \mathrm{X}_{1} \times$ $\mathrm{X}_{2}+0.20 \times \mathrm{X}_{1} \times \mathrm{X}_{3}-2.52 \times \mathrm{X}_{1} \times \mathrm{X}_{4}-1.90 \times \mathrm{X}_{2} \times \mathrm{X}_{3}+3.25 \times \mathrm{X}_{2} \times \mathrm{X}_{4}+1.45 \times$ $\mathrm{X}_{3} \times \mathrm{X}_{4}-4.03 \times \mathrm{X}_{1} \times \mathrm{X}_{1}-5.01 \times \mathrm{X}_{2} \times \mathrm{X}_{2}-4.28 \times \mathrm{X}_{3} \times \mathrm{X}_{3}-3.28 \times \mathrm{X}_{4} \times \mathrm{X}_{4}$

Table 3 shows the ANOVA results for the experimental BBD data. The determination coefficient $\left(\mathrm{R}^{2}=0.9910\right)$ indicated that less than $1.0 \%$ of the total variations were not explained by the model. Moreover, the adjusted determination coefficient $\left(\operatorname{Adj}^{2}=0.9437\right)$ confirmed that the model was highly significant. Low values of coefficient of variance (6.81) clearly indicated that the model was reproducible and reliable [24]. A Pred R-Squared of 0.9457 was reasonably consistent with an Adj R-Squared of 0.9820 . Adequate Precision was used to measure the signal-to-noise ratio. A ratio greater than 4 is desirable, and a ratio of 34.650 indicated adequate signal. This model can be used to navigate the design space.

The $\mathrm{P}$ value was used as a tool to determine the significance of each coefficient; moreover, it indicated the strength of interaction between independent variables. The smaller the P value, the more significant the corresponding coefficient would be [21]. Table 3 shows that the linear coefficients $\left(\mathrm{X}_{1}, \mathrm{X}_{2}\right.$, and $\left.\mathrm{X}_{3}\right)$, quadratic term coefficients $\left(\mathrm{X}_{1}^{2}, \mathrm{X}_{2}^{2}, \mathrm{X}_{3}^{2}\right.$, and $\left.\mathrm{X}_{4}^{2}\right)$, and cross product coefficients $\left(\mathrm{X}_{1} \mathrm{X}_{2}, \mathrm{X}_{1} \mathrm{X}_{4}, \mathrm{X}_{2} \mathrm{X}_{3}, \mathrm{X}_{2} \mathrm{X}_{4}\right.$, and $\left.\mathrm{X}_{3} \mathrm{X}_{4}\right)$ were significant, and their $\mathrm{P}$-values were very low $(\mathrm{P}<0.05)$. The other term coefficients were not significant $(\mathrm{P}>0.05)$. The full model filled Eq. (3) was made into three-dimensional and contour plots to predict the relationships between the independent and dependent variables.

Optimization of polysaccharide extraction conditions: Response surfaces were plotted using Design-Expert (version 8.0) software to study the effect of parameters on polysaccharide yield, as well as the interactions of these parameters. 3-D response surface plots and 2-D contour plots (Figures 2 and 3 ) were very useful to assess the interaction effects of the factors on the responses. These types of plots show the effects of two factors on the response at a time. In all of the plots, the two other factors were kept at level 0 . In the two plots, the maximum predicted value indicated by the surface was confined in the smallest ellipse in the contour diagram. Elliptical contours are obtained when a perfect interaction occurs between independent variables.

Figures $2 \mathrm{a}$ and $3 \mathrm{a}$ show the effect of water-to-raw material ratio, extraction temperature, and their reciprocal interaction on extraction yield when extraction time and microwave power were fixed at level 0 . A strong interaction between these factors were observed. The polysaccharide yield decreased at the designed extraction temperature range $\left(40^{\circ} \mathrm{C}-60^{\circ} \mathrm{C}\right)$, and a quadratic effect on the response yield was observed when the water-to-raw material ratio increased from 15 to 25 . The maximum extraction yield could be achieved at a water-to-raw material ratio and extraction temperature of approximately 20 and $50^{\circ} \mathrm{C}$, respectively.

Figures $2 \mathrm{~b}$ and $3 \mathrm{~b}$ show the $3-\mathrm{D}$ response surface plot and contour plot under varying extraction temperatures and microwave powers at a fixed water-to-raw material ratio (level 0 ) and extraction time (level 0 ). The plots indicate that the polysaccharide yield increased at $40^{\circ} \mathrm{C}-52^{\circ} \mathrm{C}$

\begin{tabular}{|c|c|c|c|c|c|}
\hline Source & ss & DF & MS & F value & P value Prob.>F \\
\hline Model & 671.27 & 14 & 47.95 & 110.32 & $<0.0001$ \\
\hline$x_{1}$ & 32.42 & 1 & 32.42 & 74.60 & $<0.0001$ \\
\hline $\mathrm{X}_{2}$ & 29.68 & 1 & 29.68 & 68.29 & $<0.0001$ \\
\hline $\mathrm{X}_{3}$ & 10.08 & 1 & 10.08 & 23.20 & 0.0003 \\
\hline $\mathrm{X}_{4}$ & 0.11 & 1 & 0.11 & 0.25 & $0.6276^{\text {ns }}$ \\
\hline $\mathrm{X}_{1} \mathrm{X}_{2}$ & 190.08 & 1 & 190.08 & 437.34 & $<0.0001$ \\
\hline $\mathrm{X}_{1} \mathrm{X}_{3}$ & 0.17 & 1 & 0.17 & 0.39 & $0.5440^{\text {ns }}$ \\
\hline $\mathrm{X}_{1} \mathrm{X}_{4}$ & 27.67 & 1 & 27.67 & 63.67 & $<0.0001$ \\
\hline $\mathrm{X}_{2} \mathrm{X}_{3}$ & 14.40 & 1 & 14.40 & 33.14 & $<0.0001$ \\
\hline $\mathrm{X}_{2} \mathrm{X}_{4}$ & 36.67 & 1 & 36.67 & 84.38 & $<0.0001$ \\
\hline $\mathrm{X}_{3} \mathrm{X}_{4}$ & 8.38 & 1 & 8.38 & 19.28 & 0.0006 \\
\hline $\mathrm{X}_{1}^{2}$ & 103.48 & 1 & 103.48 & 238.08 & $<0.0001$ \\
\hline$X_{2}^{2}$ & 162.60 & 1 & 162.60 & 374.12 & $<0.0001$ \\
\hline$X_{3}^{2}$ & 116.86 & 1 & 116.86 & 268.86 & $<0.0001$ \\
\hline$X_{4}^{2}$ & 69.88 & 1 & 69.88 & 160.79 & $<0.0001$ \\
\hline Residual & 6.08 & 14 & 0.43 & & \\
\hline Lack of Fit & 6.08 & 10 & 0.61 & & \\
\hline Pure Error & 0.000 & 4 & 0.000 & & \\
\hline Cor Total & 677.35 & 28 & & & \\
\hline SD & 0.66 & & \multicolumn{2}{|c|}{$\mathbf{R}^{2}$} & 0.9910 \\
\hline Mean & 9.68 & & \multicolumn{2}{|c|}{ Adj $R^{2}$} & 0.9820 \\
\hline CV (\%) & 6.81 & & \multicolumn{2}{|c|}{ Pred $\mathbf{R}^{2}$} & 0.9457 \\
\hline PRESS & 36.79 & & \multicolumn{2}{|c|}{ Adequate Precision } & 34.650 \\
\hline
\end{tabular}

Table 3: Analysis variance of experimental of the BBD. 


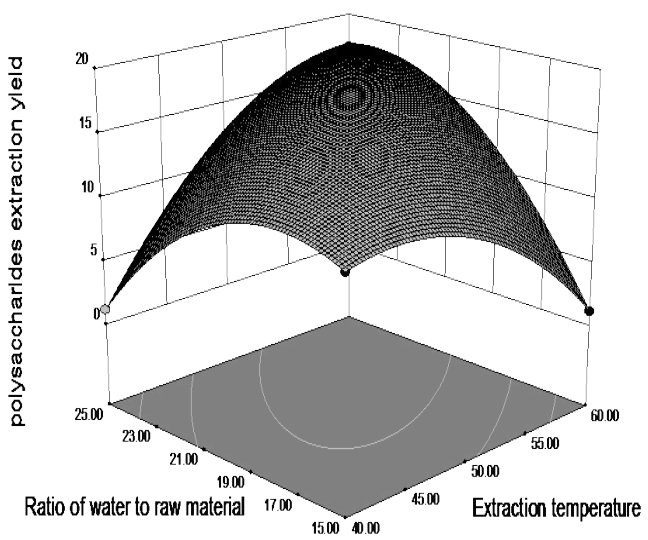

a

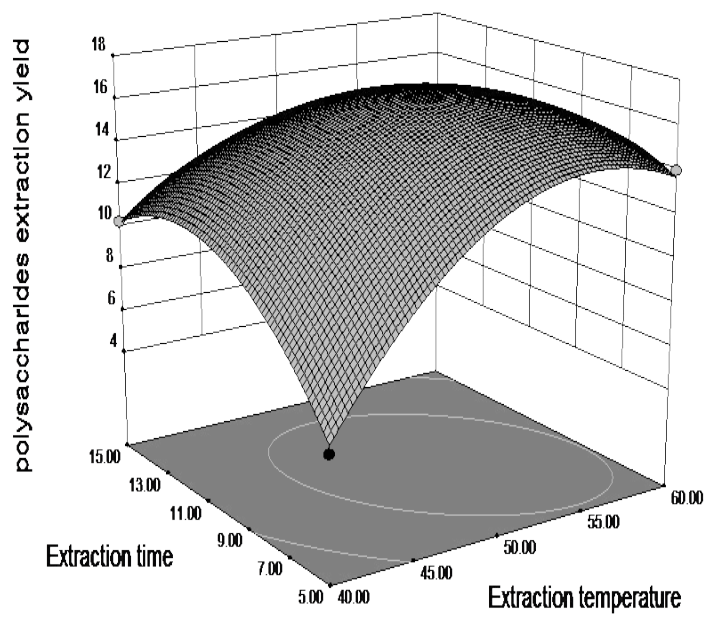

c

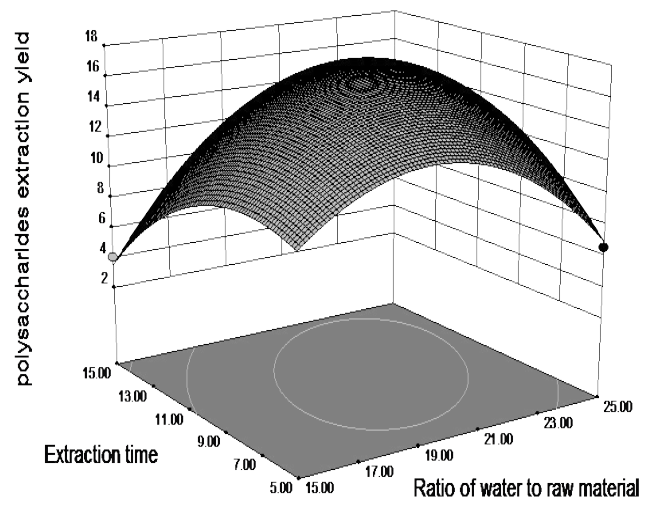

e

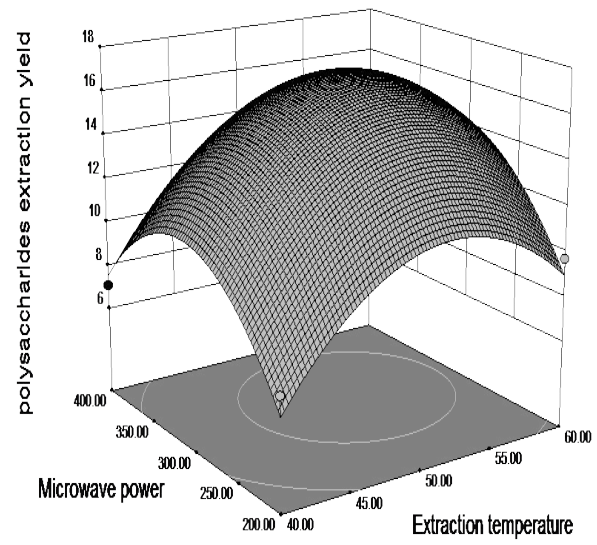

b

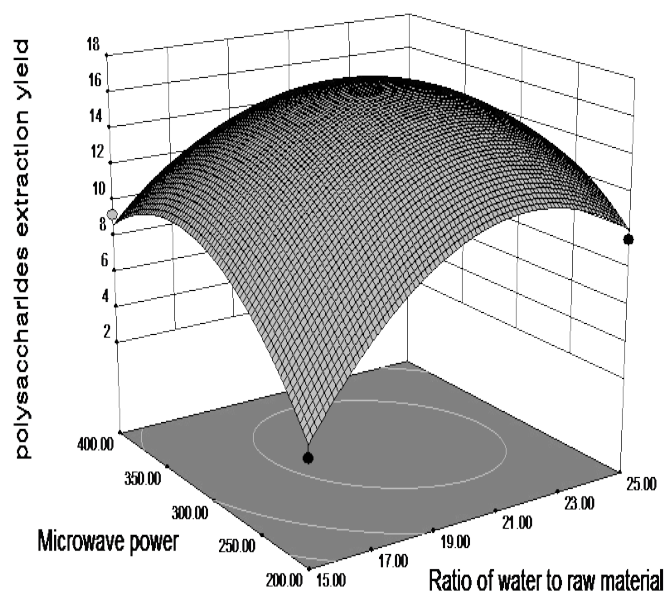

d

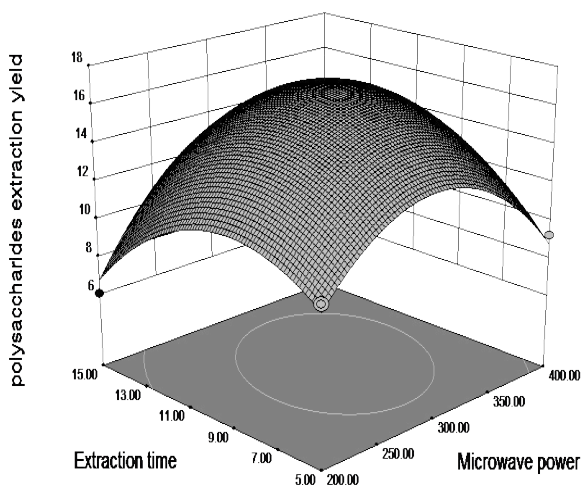

f

Figure 2: Response surface plots (3-D) showing the effects of variables $\left(\mathrm{X} 1\right.$ : extraction temperature, ${ }^{\circ} \mathrm{C} ; \mathrm{X} 2$ : ratio of water to raw material; $\mathrm{X} 3$ : microwave power, $\mathrm{W}$; and $\mathrm{X} 4$ : extraction time, $\mathrm{min}$ ) on the response $\mathrm{Y}$. 


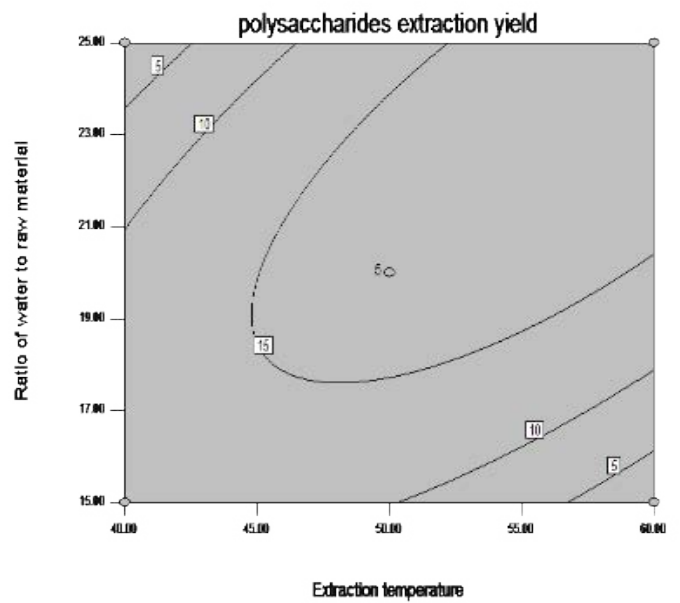

a

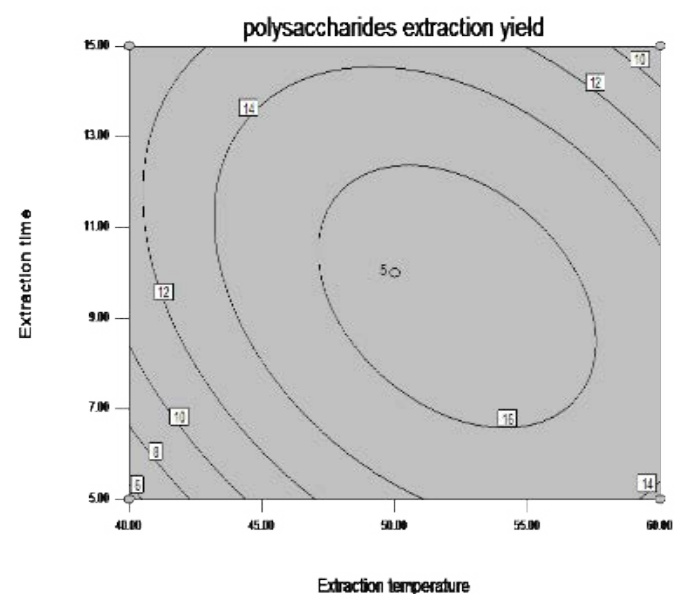

C

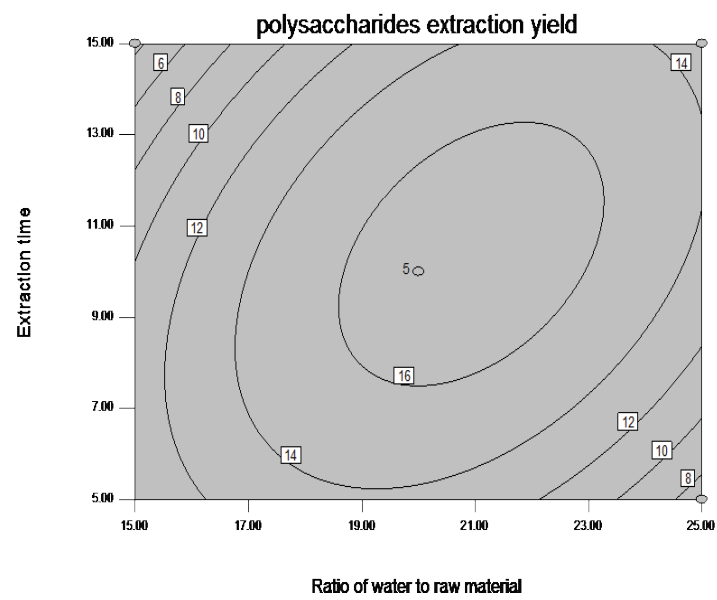

e

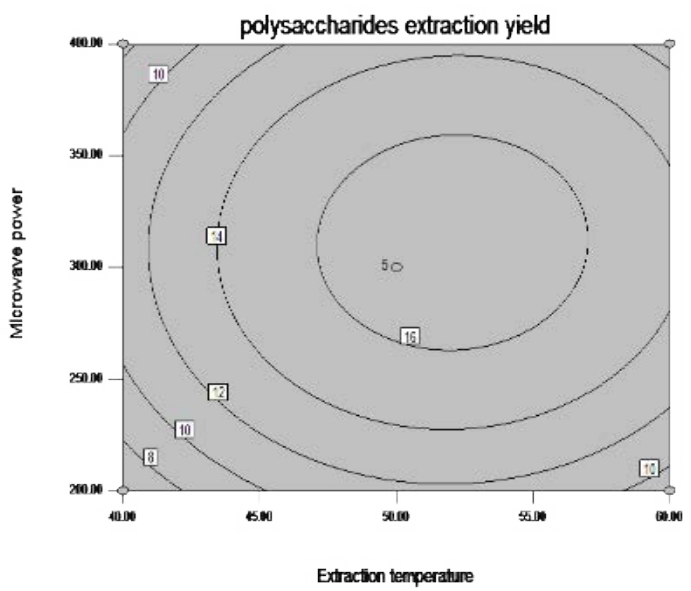

b

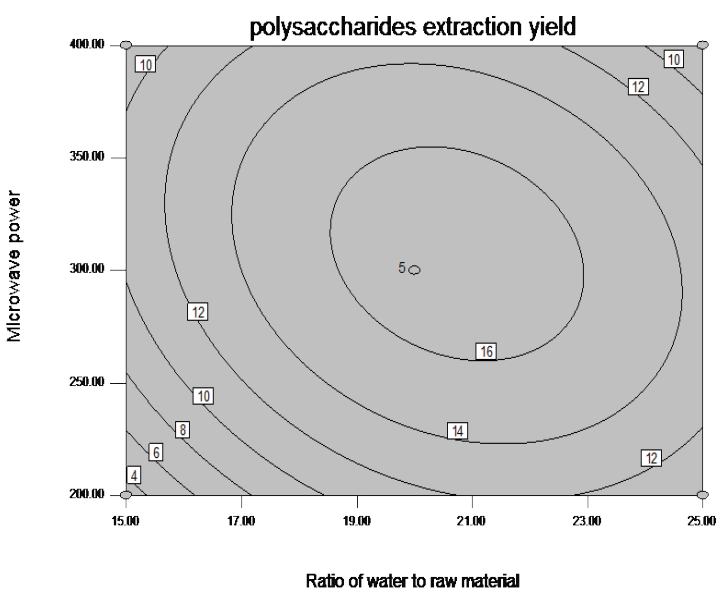

d

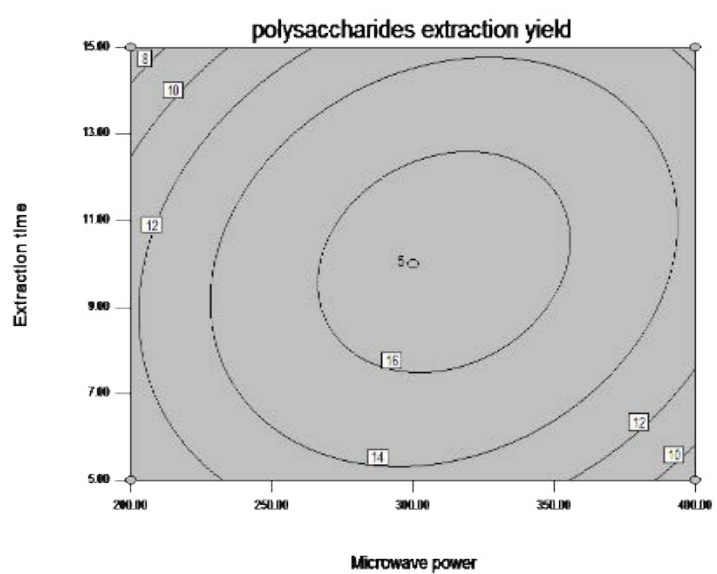

f

Figure 3: Contour plots (2D) showing the effects of variables $\left(\mathrm{X} 1\right.$ : extraction temperature, ${ }^{\circ} \mathrm{C}$; $\mathrm{X} 2$ : ratio of water to raw material; $\mathrm{X} 3$ : microwave power, $\mathrm{W}$; and $\mathrm{X} 4$ : extraction time, $\mathrm{min}$ ) on the response $\mathrm{Y}$. 
Citation: Xiao-ri Z, Li-li X, Feng X, Xiao-lin L, Chun-na Y, et al. (2016) Optimization of Polysaccharide Extraction from Polygonatum odoratum by Response Surface Methodology and Evaluation of its Antitumor Activity. J Bioprocess Biotech 6: 292. doi:10.4172/2155-9821.1000292

Page 7 of 8

and then decreased slightly at $52^{\circ} \mathrm{C}-60^{\circ} \mathrm{C}$. The polysaccharide extraction yield increased evidently with increased microwave power from $200 \mathrm{~W}$ to $311 \mathrm{~W}$; the polysaccharide yield decreased beyond $311 \mathrm{~W}$.

The POP yield was affected by different extraction temperatures and extraction times (Figures $2 c$ and $3 c$ ) when the water-to-raw material ratio and microwave power were fixed at level 0 . The maximum polysaccharide yield was obtained when the extraction temperature and extraction time.

Figures $2 \mathrm{~d}$ and $3 \mathrm{~d}$ show the $3-\mathrm{D}$ response surface plot and the contour plot under varying water-to-raw material ratios and microwave power values at a fixed extraction temperature (level 0 ) and extraction time (level 0). During polysaccharide extraction, the water-to-raw material ratio and microwave power demonstrated quadratic effects on the extraction yields. The optimal range of microwave power was 250 $350 \mathrm{~W}$ and that of water-to-raw material ratio was 18-22.5.

Figures $2 \mathrm{e}$ and $3 \mathrm{e}$ show the plots based on the independent variables water-to-raw material ratio and extraction time when the extraction temperature and microwave power were kept at level 0 . The maximum extraction yield could be achieved when the extraction time and waterto-raw material ratio were $10 \mathrm{~min}$ and 20 , respectively.

Figures $2 \mathrm{f}$ and $3 \mathrm{f}$ show the plots under varying microwave power and extraction time values under a fixed extraction temperature (level 0 ) and water-to-raw material ratio (level 0 ). The extraction yield increased with increased microwave power from $200 \mathrm{~W}$ to $325 \mathrm{~W}$; beyond $325 \mathrm{~W}$, the yield decreased with increasing extraction time. The influence of extraction time was similar to that of the microwave power, and $10 \mathrm{~min}$ was the critical extraction time. Extraction time and microwave power both exerted a positive impact on POP yields.

Based on Figures 2 and 3 and on the results of the above singleparameter study, the optimal extraction conditions for POP extraction are as follows: a temperature of $57.21^{\circ} \mathrm{C}$, a water-to-raw material ratio of 23.23, a microwave power of $298.51 \mathrm{~W}$, and an extraction time of $10.12 \mathrm{~min}$. Among the four extraction parameters studied, extraction temperature was the most significant factor affecting the POP extraction yield successively followed by water-to-raw material ratio, microwave power, and extraction time based on the significance of regression coefficients of the quadratic polynomial model (Table 3) and on gradient of slope in the 3-D response surface plot (Figure 2).

Verification of the predictive model: The suitability of the models in predicting optimum response values was tested under the following conditions: extraction temperature of $57^{\circ} \mathrm{C}$, water-to-raw material ratio of 23:1, microwave power of $300 \mathrm{~W}$, and extraction time of $10 \mathrm{~min}$. This set of conditions was determined to be optimum through RSM optimization; moreover, this set of condition was used to experimentally validate and predict response values by using the model. A mean value of $17.49 \% \pm 0.64 \%(n=3)$ was obtained from real experiments. The results indicated that the RSM approach effectively optimized the conditions for POP extraction, suggesting that the regression model was accurate and adequate for polysaccharide extraction (Table 4).

Anti-tumor activity in vitro: The inhibition effects of different POP concentrations $(4,40,400 \mu \mathrm{g} / \mathrm{mL})$ were tested in two human tumor cell lines for $72 \mathrm{~h}$ and measured using the MTT method in vitro. In this experiment, POP showed different degrees of antitumor effects. Panc-1 human pancreatic carcinoma cells were incubated with different concentrations of the polysaccharides, and the results showed that POP exerted no significant toxic effect on Panc-1 cells (Figure 4).
Although 40 and $400 \mu \mathrm{g} / \mathrm{mL}$ of the polysaccharides exerted a certain degree of inhibitory effect on Panc-1, their effects were not statistically significant $[25,26]$.

Growth of A549 cells was inhibited by POP in a dose-dependent manner compared with the control, suggesting that POP $(400 \mu \mathrm{g} / \mathrm{mL})$ are significantly cytotoxic to A549 cells in vitro $(\mathrm{P}<0.01)$ (Figure 5).

\section{Conclusion}

The extraction conditions significantly influenced the POP yields. The contour and surface plots in RSM effectively estimated the effect of four independent variables (extraction temperature, water-to-raw material ratio, microwave power, and extraction time). The optimum set of the independent variables was achieved graphically in order to obtain the desired levels of crude polysaccharide. The optimal

\begin{tabular}{|c|c|c|c|c|c|}
\hline & $\begin{array}{c}\text { Extraction } \\
\text { temperature } \\
\left({ }^{\circ} \mathbf{C}\right)\end{array}$ & $\begin{array}{c}\text { Ratio of } \\
\text { water } \\
\text { to raw } \\
\text { material }\end{array}$ & $\begin{array}{c}\text { microwave } \\
\text { power (W) }\end{array}$ & $\begin{array}{c}\text { Extraction } \\
\text { time (min) }\end{array}$ & Yield (\%) \\
\hline $\begin{array}{c}\text { Optimum } \\
\text { condition }\end{array}$ & 57.21 & 23.23 & 298.51 & 10.12 & $\begin{array}{c}17.87 \\
\text { (Predicted) }\end{array}$ \\
\hline $\begin{array}{c}\text { Modified } \\
\text { conditions }\end{array}$ & 57 & 23 & 300 & 10 & 17.49 (actual) \\
\hline
\end{tabular}

Table 4: Predicted and experimental values of the responses at optimum conditions.

$$
400 \mu \mathrm{g} / \mathrm{m} 1 \quad \square 40 \mu \mathrm{g} / \mathrm{ml} \quad \mathbf{\square} 4 \mu \mathrm{g} / \mathrm{ml}
$$

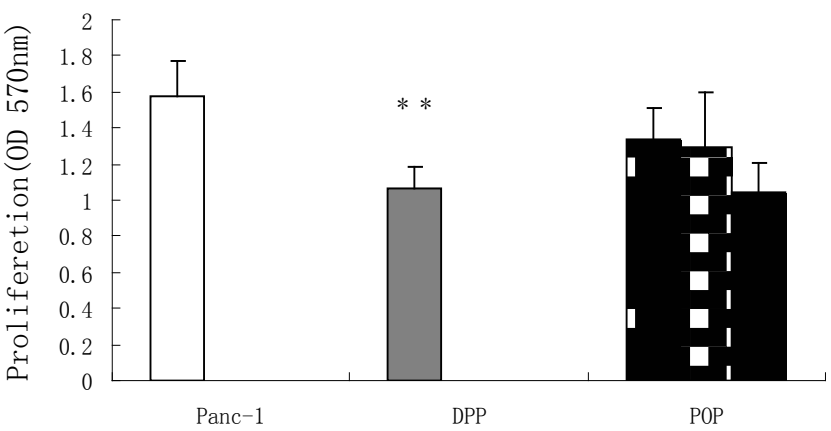

Figure 4: Effect of POP on the Panc-1 cells in vitro. Panc-1 was stimulated with $\mathrm{POP}$ at the concentrations of $400,40,4 \mu \mathrm{g} / \mathrm{mL}$ for $72 \mathrm{~h}$. After the incubation, cell proliferation was measure by the MTT assay. DDP, positive, $10 \mu \mathrm{g} / \mathrm{mL}$. Values were expressed as mean $\pm S D$. ${ }^{*} P<0.05$ vs control, ${ }^{* *} P<0.01$ vs control.

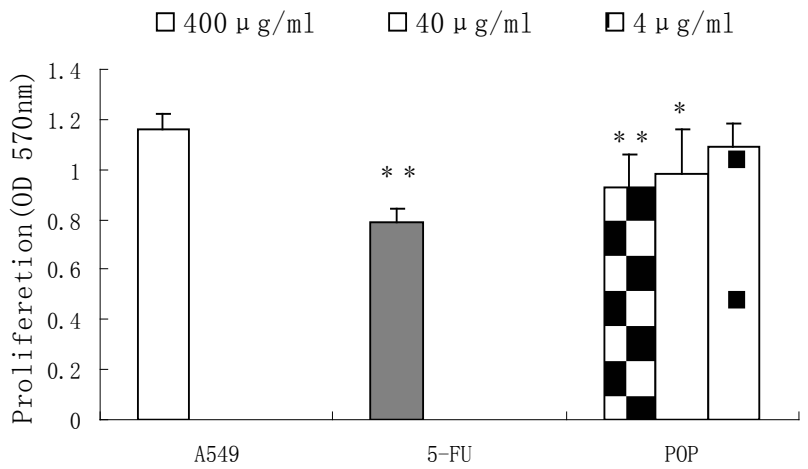

Figure 5: Effect of POP on the A549 cells in vitro. A549 was stimulated with POP at the concentrations of $400,40,4 \mu \mathrm{g} / \mathrm{mL}$ for $72 \mathrm{~h}$. After incubation, cell proliferation was measured by the MTT assay. $5-\mathrm{Fu}$, positive, $1 \mu \mathrm{g} / \mathrm{mL}$. Values were expressed as mean $\pm S D$. ${ }^{*} P<0.05$ vs control, ${ }^{* *} P<0.01$ vs control. 
Citation: Xiao-ri Z, Li-li X, Feng X, Xiao-lin L, Chun-na Y, et al. (2016) Optimization of Polysaccharide Extraction from Polygonatum odoratum by Response Surface Methodology and Evaluation of its Antitumor Activity. J Bioprocess Biotech 6: 292. doi:10.4172/2155-9821.1000292

experimental yield of $17.49 \%$ was obtained when the conditions for POP extraction were as follows: extraction temperature of $57^{\circ} \mathrm{C}$, waterto-raw material ratio of 23 , microwave power of $300 \mathrm{~W}$, and extraction time of $10 \mathrm{~min}$. Under these optimized conditions, the experimental extraction yield is close to the predicted yield.

\section{Acknowledgements}

This research was financially supported by the National Natural Science Foundation of China (Nos. 31060193 and 31200269), the Natural Science Foundation of Guangxi Province (2014GXNSFBA118134), the Guangxi Key Laboratory of Electrochemical and Magneto-chemical Functional Materials (EMFM20162205)

\section{References}

1. Yin G, Dang Y (2008) Optimization of extraction technology of the Lycium barbarum polysaccharides by Box-Behnken statistical design. Carbohydr Polym 74: 603-610.

2. Li X, Ma Y, Liu X (2007) Effect of the Lycium barbarum polysaccharides on age-related oxidative stress in aged mice. J Ethnopharmacol 111: 504-511.

3. Cui JJ, Yuan JF, Zhang ZQ (2010) Anti-oxidation activity of the crude polysaccharides isolated from Polygonum Cillinerve (Nakai) Ohwi in immunosuppressed mice. J Ethnopharmacol 132: 512-517.

4. Wang C, Zhang J, Wang F, Wang Z (2013) Extraction of crude polysaccharides from Gomphidius and their antioxidant activities in vitro. Carbohydr Polym 94: 479-486.

5. Sinha S, Astani A, Ghosh T, Schnitzler P, Ray B (2010) Polysaccharides from Sargassum tenerrimum: Structural features, chemical modification and antiviral activity. Phytochemistry 71: 235-242.

6. Zhu H, Di H, Zhang Y, Zhang J, Chen D (2009) A protein-bound polysaccharide from the stem bark of Eucommia ulmoides and its anti-complementary effect. Carbohydr Res 344: 1319-1324.

7. $\mathrm{Xu} \mathrm{H}$, Zhang $\mathrm{Y}$, Zhang J, Chen $\mathrm{D}$ (2007) Isolation and characterization of an anti-complementary polysaccharide D3-S1 from the roots of Bupleurum smithii. Int Immunopharmacol 7: 175-182

8. Li XC, Yang CR, Matsuura H, Kasai R, Yamasaki K (1993) Steroid glycosides from Polygonatum prattii. Phytochemistry 33: 465-470.

9. Chen H, Feng R, Guo Y, Sun L, Zhou Y, et al. (2001) Toxicity studies of rhizoma polygonati odorati. J Ethnopharmacol $74: 221-224$

10. Shu XS, Lv JH, Tao J, Li GM, Li HD, et al. (2009) Antihyperglycemic effects of total flavonoids from Polygonatum odoratum in STZ and alloxan-induced diabetic rats. J Ethnopharmacol 124: 539-543.

11. Xu L, Zhan X, Zeng Z, Xie T (2011) Advances in Polygonatum Odoratum. Polysaccharides 34: 154-157.
12. Wang J, Zhang J, Wang $X$, Zhao B, Wu Y, et al. (2009) A comparison study on microwave-assisted extraction of Artemisia sphaerocephala polysaccharides with conventional method: Molecule structure and antioxidant activities evaluation. Int J Biol Macromol 45: 483-492.

13. Wang J (2009) A study on microwave-assisted extraction of Artemisia.

14. Chen Y, Gu X, Huang SQ, Li J, Wang X, et al. (2010) Optimization of ultrasonic/ microwave assisted extraction (UMAE) of polysaccharides from Inonotus obliquus and evaluation of its anti-tumor activities. Int J Biol Macromol 46: 429-435.

15. Chen Y (2010) Optimization of ultrasonic/microwave assisted. Int J Biol Macromol.

16. Wang J, Zhang J, Zhao B, Wang X, Wu Y, et al. (2010) A comparison study on microwave-assisted extraction of Potentilla anserina $L$. polysaccharides with conventional method: Molecule weight and antioxidant activities evaluation Carbohydr Polym 80: 84-93.

17. Wei X, Chen M, Xiao J, Liu Y, Yu L, et al. (2007) Composition and bioactivity of tea flower polysaccharides obtained by different methods. Carbohydr Polym 79: 418-422.

18. Wang S, Chen F, Wu J, Wang Z, Liao X, et al. (2007) Optimization of pectin extraction assisted by microwave from apple pomace using response surface methodology. J Food Eng 78: 693-700.

19. Xu X, Gao Y, Liu G, Wang Q, Zhao J (2008) Optimization of supercritical carbon dioxide extraction of sea buckthorn (Hippophaë thamnoides L.) oil using response surface methodology. Food Sci Technol Int 41: 1223-1231.

20. Dubois M, Gilles KA, Hamilton JK, Rebers PA, Smith F (1956) Colorimetric method for determination of sugars and related substances. J Anal Chem 28 350-356.

21. Kim S, Asnin L, Assefa AD, Ko EY, Sharma K, et al. (2014) Extraction of Antioxidants from Aloe vera Leaf Gel: a Response Surface Methodology Study. Food Anal Methods 7: 1804-1815.

22. Jiao L, Li X, Li T, Jiang P, Zhang L, et al. (2009) Characterization and anti-tumo activity of alkali-extracted polysaccharide from Enteromorpha intestinalis. Int Immunopharmacol 9: 324-329.

23. Ye CL, Jiang CJ (2011) Optimization of extraction process of crude polysaccharides from Plantago asiatica $L$. by response surface methodology. Carbohydr Polym 84: 495-502.

24. Hou XJ, Chen W (2008) Optimization of extraction process of crude polysaccharides from wild edible BaChu mushroom by response surface methodology. Carbohydr Polym 72: 67-74

25. Sun Y, Li T, Yan J, Liu J (2010) Technology optimization for polysaccharides (POP) extraction from the fruiting bodies of Pleurotus ostreatus by BoxBehnken statistical design. Carbohydr Polym 80: 242-247.

26. Tahmouzi S (2014) Optimization of polysaccharides from Zagros oak leaf using RSM: Antioxidant and antimicrobial activities. Carbohydr Polym 106: 238-246. 